\title{
A relação família-escola como alvo das atuais políticas públicas educacionais: uma discussão necessária
}

\author{
The family-school relation as aim of current educational policies: a necessary \\ discussion
}

\section{La relación familia-escuela como un objetivo de las políticas educativas actuales: un debate necesario}

\author{
Luana Ferrarotto' \\ Maria Marcia Sigrist Malavasi" \\ 'Instituto Federal de Educação, Ciência e Tecnologia de São Paulo, Câmpus Bragança Paulista. \\ Universidade Estadual de Campinas, São Paulo - Brasil. E-mail: luanaferrarotto@yahoo.com.br \\ "Universidade Estadual de Campinas, São Paulo - Brasil. E-mail: mmarcia@unicamp.br
}

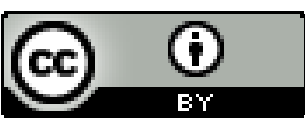

Educação: teoria e prática, Rio Claro, SP, Brasil - eISSN: 1981-8106

Está licenciada sob Licença Creative Common

\section{Resumo}

Este artigo discute a relação família-escola enquanto alvo das atuais políticas públicas educacionais, utilizando como metodologia a pesquisa bibliográfica da área. Analisando tanto o Plano Nacional de Educação quanto o Compromisso Todos pela Educação, percebe-se a relação família-escola como uma vertente de "mão única" já que atribui às famílias, apenas, a função de acompanhar os eventos escolares e as tarefas de casa. Nesse contexto, a concepção de qualidade educacional vincula-se, restritamente, aos resultados das avaliações externas e os pais são chamados a participar, inclusive esperando deles a cobrança de melhorias em relação às escolas sem a necessária análise das condições e da realidade institucional. Sabe-se que o discurso de aproximação entre família e escola é defendido pelos educadores, no entanto, deve-se reconhecer que tal discurso foi ressignificado pelas políticas públicas educacionais em curso e se distancia da cumplicidade entre família-escola ancorada na confiança e na partilha solidária de funções com pactos estabelecidos para bem da comunidade escolar.

Palavras-chave: Família e escola. Participação. Políticas Educacionais. 


\begin{abstract}
This paper discusses the family-school relationship as a target of the current educational policies, using as methodology, literature in this the area. Analyzing both the National Plan for Education and the All for Education Commitment, it is clear to notice that the familyschool relationship is a "one-way" element since it is assigned to families only the task of monitoring the school activities and homework assignments. In this context, the concept of educational quality is linked, strictly, to the results of external evaluations, and parents are invited to participate, including expecting them to suggest improvements to schools without the necessary analysis of the conditions and institutional reality. It is known that the speech about the approach between family and school is defended by educators, however, it must be recognized that such speech was reframed by the current policies and is far from the complicity between school-family anchored on trust and solidarity sharing of the functions with established for the good of the school community.
\end{abstract}

Keywords: Family and School. Participation. Educational Policies.

\title{
Resumen
}

En este artículo se analiza la relación familia-escuela como un objetivo de las políticas educativas actuales, utilizando como metodología de la literatura de la zona. Analizando tanto el Plan Nacional de Educación y el Compromiso Todos por la Educación, vemos la relación familia-escuela como un elemento de "una sola vía", ya que concede a las familias solamente, la tarea de supervisar las actividades de la escuela y las tareas escolares. En este contexto, el concepto de calidad educativa se vincula, en sentido estricto, se invita a los resultados de las evaluaciones externas y los padres a participar, incluyendo la espera de ellas la colección de mejoras en comparación con escuelas sin el análisis necesario de las condiciones y la realidad institucional. Se sabe que el enfoque del discurso entre la familia y la escuela es defendida por los educadores, sin embargo, hay que reconocer que tal discurso fue reformulado por las políticas públicas educativas en curso y está lejos de la complicidad entre la escuela-familia anclada en la confianza y el intercambio funciones de apoyo con los convenios establecidos por el bien de la comunidad escolar.

Palabras clave: Familia y Escuela. Participación. Políticas Educativas.

\section{Introdução}

Educação: Teoria e Prática/ Rio Claro/ Vol. 26, n.52/ p. 232-246/ Mai-Ago. 2016. 
As últimas políticas educacionais, como veremos a seguir, têm estimulado o envolvimento das famílias ${ }^{1}$ na vida escolar dos seus filhos uma vez que "inúmeras pesquisas" - apesar de genéricas e com análises realizadas, apenas, a partir dos relatórios contextuais do SAEB (Sistema de Avaliação da Educação Básica) - "vêm demonstrando a influência positiva, sobre o desempenho acadêmico, do envolvimento parental na escolaridade dos filhos" (NOGUEIRA, 2006, p. 157). Assim, a relação família-escola torna-se a tônica de determinadas políticas públicas.

Nessa direção, o Plano Nacional de Educação (PNE) ${ }^{2}$, aprovado em 25 de junho de 2014, faz referência à família em 16 passagens, entre elas destacamos:

2.9) incentivar a participação dos pais ou responsáveis no acompanhamento das atividades escolares dos filhos por meio do estreitamento das relações entre as escolas e as famílias;

7.10) fixar, acompanhar e divulgar bienalmente os resultados pedagógicos dos indicadores do sistema nacional de avaliação da educação básica e do IDEB, relativos às escolas, às redes públicas de educação básica e aos sistemas de ensino da União, dos Estados, do Distrito Federal e dos Municípios, assegurando a contextualização desses resultados, com relação a indicadores sociais relevantes, como os de nível socioeconômico das famílias dos (as) alunos (as), e a transparência e o acesso público [portanto, famílias e comunidade] às informações técnicas de concepção e operação do sistema de avaliação;

19.6) estimular a participação e a consulta de profissionais da educação, alunos (as) e seus familiares na formulação dos projetos políticopedagógicos, currículos escolares, planos de gestão escolar e regimentos escolares, assegurando a participação dos pais na avaliação de docentes e gestores escolares. (PNE, 2014, grifos nossos).

Partindo do Plano Nacional de Educação, percebemos ser necessário concentrar esforços na análise sobre o papel de destaque posto às famílias nas políticas públicas educacionais. Dessa forma, a partir de um levantamento bibliográfico, propomos o debate tanto sobre as propostas educacionais em curso quanto sobre os aspectos presentes na complexa relação entre família e escola.

\section{Família-Escola: Rivais ou Aliados?}

\footnotetext{
${ }^{1}$ Usaremos, neste artigo, tanto a palavra família quanto a palavra pais para nos referirmos aos responsáveis pelos estudantes na esfera escolar.

${ }^{2}$ Lei, prevista na Constituição Federal, aprovada em 26 de junho de 2014 com validade de 10 anos. É composto por 20 metas que abrangem os níveis e as modalidades de ensino e contempla, ainda, ações voltadas ao financiamento da educação.
} 
Discutir sobre como se concretiza a relação família e escola nos instiga, pois conduz a reflexão acerca da aproximação (ou afastamento) entre as lógicas destas duas instituições enquanto possível explicação para as trajetórias escolares e, ainda, para o rendimento escolar.

De acordo com Lahire (1997, p. 38) família e escola estabelecem uma rede de interdependência na qual as relações sociais são "mais ou menos harmoniosas e contraditórias". Autores como Nogueira (2006) Lomonaco e Garrafa (2009) e Silva (2009), também ressaltam a complexidade do relacionamento entre essas duas instituições, foco de nossas reflexões. No entanto, ao analisar os escritos dos autores citados, percebemos que as diferentes formas de relação entre família-escola decorrem, muitas vezes, da origem social da primeira. Dessa forma, sobretudo quando as famílias são de classes populares, a diferença entre o que a escola estabelece como dominante e o que a família apresenta enquanto cultura são significativamente diversas.

López (2008) argumenta que a escola, na figura do professor, concebe e espera um perfil ideal de aluno, contudo, em sala de aula, se depara com algo bem diferente, ou seja, o professor "pressupõe uma criança com um conjunto de predisposições desenvolvidas antes de entrar na escola" (p. 330). Atrevemo-nos a dizer o mesmo quanto às escolas e as famílias: há um perfil familiar idealizado e esperado pelas escolas, no qual o acompanhamento dos deveres, a participação nos eventos e a concordância com as ações promovidas pela escola são fundamentais. Da família idealizada pela escola espera-se, ainda, um determinado modo de se vestir, de falar, de se comportar - e porque não dizer de viver. Em outras palavras, a família configura-se como "centro da cena" e, além de fornecer a seus fillhos condições saudáveis de sobrevivência, deve fornecer uma bagagem social e cultural, compatível com o exigido pela escola, colocando-as em "condições favoráveis diante das exigências escolares" (NOGUEIRA; NOGUEIRA, 2002, p. 18).

Dessa forma, o sucesso escolar, ocorre quando há uma convergência entre as duas culturas: a familiar e a escolar (BOURDIEU, 1998). A cultura escolar, através do sistema educacional definido pelas políticas governamentais - e, portanto, planejadas e implementadas por uma classe social dominante - legitima apenas um determinado modo de ser, conviver, e relacionar-se com o saber, fazendo das demais culturas alheias ao processo escolar (NOGUEIRA; NOGUEIRA, 2002, p. 28). Vale, nesse momento, dialogarmos sobre o sucesso escolar e, consequentemente, o seu oposto, ou seja, o fracasso escolar. Na seção anterior apresentamos brevemente que, de acordo com pesquisas realizadas a partir dos questionários contextuais do SAEB, há influência positiva, para o rendimento do aluno, quando existe envolvimento dos pais na vida escolar dos filhos (NOGUEIRA, 2006). Vimos, ainda, que frente ao exposto, políticas públicas para a educação são formuladas na tentativa de enaltecer e incentivar a participação dos pais em assuntos educacionais. Tais políticas, por sua vez, abarcam uma determinada concepção de qualidade para a educação assim como defendem um modo específico de relação família-escola.

Nesse sentido, propomos alguns questionamentos para reflexão: qual é a qualidade para a educação pretendida por tais políticas? Quais características, na relação família-escola, são por elas defendidas? Estariam apenas intencionadas a alinhar o perfil das famílias ao 
perfil idealizado pela escola, confirmando, dessa forma, a exclusão da cultura das famílias populares?

O PNE, recentemente aprovado, revela que a qualidade anunciada para a educação relaciona-se ao alcance de índices. Índices que são obtidos por meio de testes padronizados e que, frequentemente, tem apontado os professores e as escolas como culpados pelas médias de proficiências dos alunos, sobretudo quando elas estão abaixo do esperado. Existe, portanto, uma perversa e dupla culpabilização: as famílias por não terem acompanhado o estudo dos filhos uma vez que a oportunidade de escolarização foi disponibilizada, e na outra ponta estão os professores, responsabilizados por não terem "transmitido as informações"3 necessárias para a identificação das respostas corretas dos testes.

Vale destacar que, na mesma direção do PNE, o Compromisso "Todos pela Educação", instituído ${ }^{5}$ simultaneamente ao Plano de Desenvolvimento da Educação (PDE), também incentiva a aproximação entre família-escola. Assim, o conjunto de empresas ${ }^{6}$ que compõem o Compromisso "Todos pela Educação", apresenta a implementação de suas propostas a partir da colaboração dos Municípios, do Distrito Federal e dos Estados e "a participação das famílias e da comunidade, mediante programas e ações de assistência técnica e financeira, visando à mobilização social pela melhoria da qualidade da educação básica" (BRASIL, 2007). Mais uma vez a qualidade está associada aos índices, já que em seu segundo capítulo (o primeiro institui o "Compromisso Todos pela Educação"), o Decreto 6.094 faz referência ao Índice de Desenvolvimento da Educação Básica (IDEB).

Em consulta ao site do "Todos pela Educação", identificamos que, em 2014, foram produzidas quatro reportagens ${ }^{7}$ que fazem referência a importância do acompanhamento, por parte dos pais, da vida escolar de seus filhos, como forma de aumentar os resultados obtidos. São elas:

- "Temos que fortalecer o diálogo entre escola e família" (13 de outubro de 2014): destaca a importância dos pais acompanharem as lições de casa e as reuniões promovidas pela escola. Há, ainda, menção a relevância de se estabelecer "diálogos que façam links com os conteúdos vistos na escola".

\footnotetext{
${ }^{3}$ Fazemos referência a transmissão de informações, pois muitas pesquisas (ARCAS, 2009, FERRAROTTO, 2011, RAVITICH, 2013, SCHNEIDER, 2013) apontam que, entre os impactos dos testes padronizados estão: estreitamento curricular e treinamento intensivo para os testes.

${ }^{4}$ Fundado em 2006 e instituído enquanto "Compromisso Todos pela Educação", pelo decreto 6.094, em 24 de abril de 2007, o Todos pela Educação é composto por grupos empresariais que tem por objetivo, "em regime de colaboração com Municípios, Distrito Federal e Estados, e a participação das famílias e da comunidade" (BRASIL, 2007), a partir de 5 metas, propiciar condições de acesso, alfabetização, sucesso escolar, ampliação de investimentos e melhoria na gestão dos recursos educacionais.

${ }^{5}$ Decreto 6.094.

${ }^{6}$ Algumas empresas que compõem o Todos pela Educação são: Grupo Pão de Açúcar, Fundação Itaú-Social, Fundação Bradesco, Instituto Gerdau, Grupo Gerdau, Fundação Roberto Marinho, Fundação Educar-DPaschoal, Instituto Itaú Cultural, Faça Parte-Instituto Brasil Voluntário, Instituto Ayrton Senna, Cia. Suzano, Banco ABNReal, Banco Santander, Instituto Ethos.

${ }^{7}$ Período compreendido na busca ao site: 01 de janeiro de 2014 a 20 de novembro de 2014.
} 
- "Todos Pela Educação lança 5 Atitudes pela Educação" (14 de outubro de 2014): conjunto de iniciativas (5 atitudes) que devem ser adotadas pelas famílias, escolas e comunidade na busca da melhoria da qualidade da educação básica.

- "Estudos sociológicos investigam a relação entre família e escola" (4 de novembro de 2014): apresenta pesquisas que "tentam dimensionar e mapear as atitudes e comportamentos de responsáveis que impactam a relação das crianças e jovens com a escola" ${ }^{\prime}$.

- "Pesquisa revela perfis de pais em relação à Educação dos filhos" (06 de novembro de 2014): a pesquisa teve como objetivo identificar atitudes dos familiares que impactam a relação do estudante com a escola. (TODOS PELA EDUCAÇÃO, 2014).

Como podemos perceber, as reportagens posicionam as famílias enquanto participantes da vida escolar de seus filhos, apenas de modo complementar as ações escolares, com o acompanhamento dos eventos e das tarefas de casa. Não negamos a importância do acompanhamento das atividades escolares por parte das famílias. Nossa intenção, com esta discussão, é alertar para a configuração da relação família-escola nas atuais propostas governamentais, pois como afirma Saviani (2007, p. 1253), estamos frente a uma "“pedagogia de resultados': o governo se equipa com instrumentos de avaliação dos produtos, forçando, com isso, que o processo se ajuste às exigências postas pela demanda das empresas" (grifos do autor).

A relação entre família-escola, dessa forma, é posta de forma simplista e reducionista e não de uma forma complexa e dialética que envolve o contexto no qual as escolas e as famílias se localizam. Autores nacionais (FREITAS, 2013; TRAVITZKI, 2013) e internacionais (RAVITCH, 2013) têm apontado o quanto o nível socioeconômico determina os resultados escolares. Dessa forma, a análise acerca do sucesso escolar, ou o seu oposto, deve ser feita sob a ótica do contexto escolar, caso contrário, a leitura dos resultados dos testes de alto impacto será fornecida por uma visão míope do processo de ensinoaprendizagem.

Como alerta Freitas (2013, p. 363) " $50 \%$ a $60 \%$ das variáveis que afetam a proficiência dos alunos são externas às escolas”, nesse sentido, é preciso interpretar as variáveis externas a escola enquanto políticas públicas necessárias. Moradia, saúde pública,

\footnotetext{
${ }^{8}$ Tal reportagem faz referência ao trabalho de Portes (2000), Romanelli (2003) e Bandera (2014). Dos trabalhos mencionados são intensificadas as passagens que vinculam o papel da família ao sucesso escolar desconsiderando a análise sociológica das condições econômicas e culturais. Em especial, sobre o artigo de Portes (2000) a reportagem ressalta que os "alunos que vieram de famílias pobres, estudaram a vida inteira em escolas públicas e, apesar das adversidades (econômicas inclusive, já que são filhos de trabalhadores de baixa renda), entraram na universidade federal em carreiras disputadas, como Medicina e Engenharia”. (PORTES, 2000). Nesse sentido, faz um recorte tendencioso, ao apresentar uma relação direta entre sucesso escolar, esforço individual e envolvimento familiar. Há uma grande quantidade de variáveis a ser considerada na análise quanto ao sucesso/fracasso escolar, sobretudo o nível socioeconômico dos alunos. (FREITAS, 2013; RAVITCH, 2013; TRAVITZKI, 2013).
} 
segurança, cultura e o combate à miséria são essenciais para que, além da oportunidade de acesso à escola, seja garantido a permanência e o êxito escolar ${ }^{9}$.

Ravitch (2013), em seus escritos, defende a ampliação das ações de políticas públicas para outras esferas interligadas a educação, como forma de enfrentamento da problemática escolar. Dessa forma, desde as condições essenciais de sobrevivência - como o acompanhamento gestacional, a nutrição das crianças, os primeiros acompanhamentos médicos - até a infraestrutura, as práticas escolares e as condições de trabalho dos professores - bibliotecas, tamanho reduzido das salas de aula, ampla grade curricular (para além de leitura e matemática, com aulas de artes, ciência, geografia, história, língua estrangeira), a formação de professores, a estabilidade e a segurança na carreira - devem ser foco de políticas realmente comprometidas com a formação integral ${ }^{10}$ do estudante e seu sucesso escolar.

Entre tantos aspectos importantes levantados por Ravitch (2013), destacamos o uso dos resultados das avaliações externas. Para a autora, "os resultados dos testes devem ser informações confidenciais disponíveis apenas para estudantes, pais, professor e, se necessário, dirigentes $^{11}$ " (RAVITCH, 2013, p. 259, traduzido por nós). Apesar de parecer semelhante ao defendido pelo PNE, sobre o acompanhamento e divulgação dos resultados dos sistemas de avaliação (Meta 7.10), há uma grande diferença quando o Projeto Político-Pedagógico da escola é discutido por sua comunidade (funcionários, gestores, professores, alunos e famílias) de forma confidencial e a partir de seu contexto.

A relação família-escola, quando o principal objetivo em comum é a formação integral do estudante, não aponta culpados na tentativa de identificar quem cumpriu ou não sua função. Ao estabelecer um diálogo horizontal, vislumbrando melhorias, pactos são estabelecidos entre os diversos segmentos que, dessa forma, não são rivais e sim aliados. Ao colocar família e escola em relação conflituosa, de culpabilização, instaura-se a lógica mercadológica: o Estado cumprido seu papel de avaliar as escolas, divulgando amplamente seus resultados, as famílias buscando os responsáveis pelas proficiências obtidas por seus filhos e, consequentemente, "escolhendo" aquelas instituições com professores que podem ofertar um melhor ensino.

Os Estados Unidos da América, berço das políticas de responsabilização docente via testes padronizados, também concebem as famílias enquanto "agentes fiscais" dos resultados escolares. A lei No Child Left Behind (NCLB), assinada em janeiro de 2002 pelo presidente Bush, em seu quarto princípio destaca: "Promover o conhecimento, por parte das famílias, do

\footnotetext{
${ }^{9}$ Para Luiz Carlos de Freitas (2007), o discurso liberal prega a igualdade de oportunidades e não igualdade de resultados. Os resultados, na visão liberal, dependem dos méritos e esforços individuais e são, portanto, obtidos via competição. Todavia, as desigualdades econômicas e sociais, criadas pelo sistema comandado pelos próprios liberais, são descartadas em seus discursos, pois, como defendido por eles, o acesso já foi concedido. Mais detalhes ver Freitas (2007).

${ }^{10}$ Para nós a formação integral do estudante vai além dos aspectos cognitivos verificados nas provas. Trata-se de uma formação que promove o desenvolvimento afetivo, social, físico e político e desperta a criticidade, a criatividade e a sensibilidade, favorecendo a atuação do estudante nos diversos ambientes sociais de forma solidária e emancipadora.

11 "[...] treat the test scores of individual studentes as confidencial information available only to students, parents, teachers, and, if need, the principal".
} 
rendimento das escolas e dos programas inovadores implementados". (E.U.A., 2001). Os pais são vistos, nessa perspectiva como "as melhores forças de prestação de contas na área da educação”. (E.U.A., 2001, grifos nossos). Ao contrário do que se esperava, as propostas para a educação de Barack Obama, intensificaram a lógica mercadológica com a Race to the Top. Para Ravitch (2013) "há pouca diferença entre a Race to the Tope e a NCLB. O programa de Barack Obama preservou os testes, accontability, e a escolha [de escolas pelas famílias, via vouchers] no centro da agenda federal ${ }^{12}$." (RAVITCH, 2013, p. 40, traduzido por nós, grifos nossos). Nessa perspectiva, de acordo com Bauer (2008), ocorre uma combinação entre "regulação do Estado e a lógica do mercado na oferta e gerenciamento dos serviços públicos." (BAUER, 2008, p. 565). Há, portanto, uma grande similaridade entre as propostas públicas brasileiras e americanas voltadas ao estreitamento dos laços entre família-escola.

A relação família-escola, no cenário apresentado, caracteriza-se pela fiscalização, cujo enfoque está em cobrar melhorias, sem a análise da realidade escolar, tomando os professores e a instituição como únicas responsáveis pela qualidade educacional. Acreditamos que tal característica não potencializa a relação entre essas duas instituições. Neste cenário, o que se pretende é um "alinhamento" entre a ideologia neoliberal e o papel da família no ambiente escolar, posicionando os últimos enquanto consumidores do sistema público de ensino. Assim, as propostas políticas voltadas à participação dos pais na vida escolar dos filhos deve ser alvo de nossa atenção, pois, como vimos, além de reduzir o papel das famílias ao acompanhamento das tarefas e presença em reuniões, induz os pais a fazerem o controle da escola e do que ela (não) oferece, posicionando-os como fiscalizadores dos serviços prestados pelas instituições e eximindo o poder público de suas responsabilidades quanto a qualidade educacional, efetuando, apenas, a avaliação das unidades escolares.

Entendemos que um posicionamento de controle, fiscalização e, portanto, desconfiança por parte das famílias, não contribui favoravelmente para a formação integral do estudante. Da mesma forma, não defendemos que as escolas devem exigir dos pais a consonância com uma cultura dominante e diferente da sua. Precisamos estar atentos à cilada que, de um lado, aponta os pais como responsáveis pelo fracasso escolar, rotulando-os como desinteressados pela educação de seus filhos e, do outro, culpabiliza os professores pelos índices obtidos nos testes padronizados.

Acreditamos que não há falta de interesse das famílias pela escola. Como afirma Lahire (1997, p. 334) há o mito da omissão parental, produzido pelos próprios professores ao ignorarem a lógica da configuração familiar e, assim, "a partir dos comportamentos e dos desempenhos escolares dos alunos" deduzem "que os pais não se incomodam com os filhos".

Além de Lahire (1997), Zago (2000), Portes (2000), Viana (2000) Lomonaco e Garrafa (2009) também identificaram, em suas pesquisas, que famílias em territórios vulneráveis atribuem valor a escola, sobretudo porque a considera como uma das raras possibilidades de uma vida melhor. Nesse sentido, como destaca Viana (2000), as práticas de

\footnotetext{
12 "There was very little difference between Race to the Top and NCLB. The Obama program preserved testing, accountability, and choice at the center of the federal agenda".
} 
tais famílias voltadas ao rendimento escolar, diferentemente das camadas médias, não são específicas e intencionais. Dessa forma, por não ocorrer um acompanhamento minucioso das atividades escolares, facilmente identificadas pela escola, as famílias, em sua maioria proveniente das camadas populares, são tidas como não valorosas da vida escolar dos filhos. Vale ressaltar que, ainda referente às famílias em situações de vulnerabilidade social, Lomonaco e Garrafa $(2009$, p. 34) identificaram que "as mães acham que devem acompanhar as lições de casa e criam estratégias para fazê-lo, mesmo as analfabetas, como conferir a data no caderno ou ver o quanto ele está preenchido" demonstrando assim interesse pelas atividades escolares.

As tendências identificadas nas pesquisas acima mencionadas nos conduzem a considerar a necessária aproximação e abertura ao diálogo entre a instituição família e a instituição escola. As escolas precisam estreitar a relação com as famílias, a fim de "ter maiores informações a respeito de quem são os alunos, suas famílias, sua cultura, sua vida cotidiana" (REALI; TRANCREDI, 2005, p. 241), e também as famílias precisam ter voz na escola e, a partir de sua realidade, contribuir na construção do Projeto Político-Pedagógico de uma forma alternativa, propositiva e emancipatória, na contramão da atual busca frenética por índices que conduz ao rompimento da relação saudável e harmoniosa entre professores e pais.

\section{Família-Escola: a Necessária Cumplicidade}

Como vimos, a relação família-escola é alvo das políticas educacionais em curso. Tais propostas, em sua maioria ao serem apoiadas por reformadores empresariais ${ }^{13}$, ressignificam o discurso que, há tempos, é defendido pelos educadores. No entanto, o discurso ressignificado, apesar de sedutor - uma vez que analisam o ambiente escolar e a qualidade educacional sob a ótica simplista da relação causa e efeito ${ }^{14}$ - apresenta princípios opostos a uma prática educativa transformadora: sua lógica carrega consigo ideais mercadológicos e meritocráticos. Para além de análises que sustentem seus argumentos na vontade de ensinar, por parte do professor, e de aprender, por parte dos alunos, é preciso olhar para a escola a partir de seu contexto. Na realidade brasileira, a instituição escolar insere-se em um sistema capitalista, cujas desigualdades produzidas ultrapassam os muros da escola. Todavia, aceitar como natural que alguns estudantes aprendem e outros não e reduzir a não aprendizagem a culpabilização de famílias e escolas é perpetuar a lógica neoliberal que, como já destacamos, sustenta que o êxito escolar vincula-se ao esforço individual, tanto de professores quanto de famílias/estudantes.

\footnotetext{
${ }^{13}$ Reformadores empresariais (corporate reformes), de acordo com Freitas (2012, p. 380) foi um termo criado pela pesquisadora americana Daiane Ravitch para fazer referência à união entre "políticos, empresários, empresas educacionais, institutos e fundações privadas e pesquisadores" que defendem o envolvimento da iniciativa privada como forma de resolver os problemas educacionais.

${ }^{14}$ A relação de causa e efeito, neste caso, diz respeito a crença que o envolvimento familiar (isoladamente) leva ao aumento dos rendimentos escolares.
} 
Vale destacar que meritocracia e mercado não combinam com educação que defendemos. Como afirma Freitas (2013) na educação não pode haver "ganhador e perdedores". Na educação, diferentemente do mercado, "não podemos conviver com perdedores" (p. 360). Dessa forma, acreditamos que quebrar o círculo vicioso, que aponta professores como responsáveis pelos resultados dos testes padronizados de seus alunos e as famílias como omissas no processo educativo, só será possível através da cumplicidade entre tais instituições, em uma perspectiva ampla, que ultrapassa o simples acompanhar de deveres escolares ou a presença em reuniões bimestrais.

Para tanto, propomos que a escola dê o primeiro passo e inicie a proposição de formas alternativas de contato com as famílias, ou seja, a construção de uma nova ponte entre esses dois mundos comuns à criança. A escola, enquanto especialista nos processos pedagógicos, e a família, enquanto primeira instância educativa da criança (DESSEN; POLONIA, 2007, p. 22), apresentam semelhanças e divergências no modo de pensar e agir que precisam ser expostas e negociadas para que a formação do estudante ocorra de maneira integral, para além dos aspectos cognitivos postos à prova nos testes de alto impacto.

Tal cumplicidade parte do Projeto-Político Pedagógico (PPP) da escola que, ao conter o registro dos caminhos já trilhados pela instituição, aberta a discussões coletivas, avalia suas ações e metas e estabelece novos acordos com a partilha de responsabilidades e a elaboração de um plano de ação que almeja o bem da comunidade escolar. Acreditamos em ações desenvolvidas que emergem da contextualização da realidade e vislumbrem o bem da comunidade, pois, para que a relação família-escola contribua com a formação integral do estudante, faz-se necessário que tal relação seja estabelecida em um contato harmonioso, de contentamento com os pactos firmados, de confiança e partilha solidária de funções.

O movimento acima descrito, em que a escola olha para dentro de si com a participação ativa de seus segmentos é tratado por Betini (2009) no contexto da Avaliação Institucional. Dessa forma, concebemos a Avaliação Institucional como ferramenta potente, alternativa e propositiva na criação de uma relação de cumplicidade entre família e escola. No entanto, romper com as tradicionais formas de relação entre tais instituições não se dá da noite para o dia. A construção é processual, complexa, contraditória e, portanto, inversa ao proposto pelo Plano Nacional de Educação que reduz a interação família-escola apenas ao acompanhamento dos deveres escolares e a avaliação, via índices, das escolas e seus profissionais.

O estudo e a reflexão da escola sobre si mesma, com a voz ativa de seus diversos segmentos, com norte em seu PPP, favorece o processo de empoderamento ${ }^{15}$ de seus atores

\footnotetext{
15 A partir da definição de Batliwala (1997), temos que o empoderamento demanda a transformação das estruturas de dominação. Manifesta-se como uma redistribuição do poder entre nações, classes, gêneros ou indivíduos. Leva ao desenvolvimento de uma nova concepção de poder, norteada pela democracia e pelo poder compartilhado com responsabilidades coletivas assumidas nos processos decisórios. Em suas palavras: "El proceso de empoderamiento es, entonces, una espiral que altera la conciencia, identifica áreas de cambio, permite crear estrategias, promueve el cambio canaliza las acciones y los resultados, que a la vez permiten alcanzar niveles mas altos de conciencia y estrategias mas acordes con las necesidades y mejor ejecutadas. Visto
} 
que, por sua vez, tornam-se instrumentalizados e protagonistas na construção da sua qualidade não enquanto uma questão optativa - de vontade ou falta de preparo dos professores ou, ainda, desleixo familiar - mas enquanto o melhor que consegue realizar a partir de suas condições. É, ainda, pela voz e força de seus atores, na discussão sobre a realidade, que aparecerão as necessárias reflexões a respeito das situações de vida das famílias e das condições de trabalho dos educadores.

Dessa forma, os processos de análise da realidade escolar, com discussões de suas fragilidades e potencialidades, favorece a formação mútua de seus membros. O exercício de ouvir e posicionar-se contribui para "uma forma de produção de conhecimento social em construção coletiva” (MENDES, 2012, p. 193) e, portanto, contribui para a análise dos fatores intra e extraescolares. Tais fatores, vistos com olhar problematizador, poderão romper com a lógica acima enunciada cuja função das famílias é reduzida a fiscalizar os resultados apresentados pela escola nos testes padronizados.

A análise dos coletivos em sua Avaliação Institucional deve, portanto, ser norteada por valores como solidariedade, responsabilização participativa ${ }^{16}$, colaboração e emancipação na contramão da lógica mercadológica em que "aqueles que ensinam são prestadores de serviço; os que aprendem são clientes e a educação é um produto que pode ser produzido com qualidade variável" (SAVIANI, 2007, p. 1253).

Assim, torna-se necessário resgatar nosso discurso de aproximação entre famíliaescola e, com a cumplicidade estabelecida entre essas duas instituições, curvar a vara em direção oposta a atual "pedagogia de resultados" (SAVIANI, 2007, p. 1253). Família e escola precisam estar próximas em uma relação cumplice, na aliança pela qualidade social. Uma qualidade comprometida com a formação do estudante e com sua comunidade, "relacionados ao campo social, à vida política, a aspectos filosóficos da vida humana" para "além de aspectos técnicos de instrução" (BETINI, 2009, p. 116).

Para tanto, o protagonismo deve estar nas mãos da escola e sua comunidade. Avaliar e planejar, no compromisso com a qualidade social, só será possível se as relações estabelecidas foram ancoradas na horizontalidade e no conhecimento profundo da realidade local. A cumplicidade família-escola, para além de presença em eventos escolares e acompanhamentos das tarefas, significa uma aliança que envolva tais instituições no estudo permanente de como era, como está e o que se deseja para a educação dos estudantes. Significa, ainda, um pacto com propósitos emancipadores de uma sociedade menos desigual, mais solidária e humana.

así, el empoderamiento en espiral afecta a todos los involucrados: el individuo, el agente activista, la colectividad y la comunidad" (BATLIWALA, 1997, p. 201).

${ }^{16}$ Processo de reflexão que objetiva incluir os atores e, sobretudo, dar-lhes poder deliberativo sobre a qualidade educacional de modo a servir a interesses emancipatórios. O coletivo escolar assume seu protagonismo e, a partir dos problemas identificados, organiza ações futuras. Trata-se, portanto, de uma contrarregulação, pois envolve diversos segmentos na defesa da qualidade educacional em direção oposta as "lógicas das políticas imediatistas e restritas a interesses específicos de setores econômicos”. (SORDI; FREITAS, 2013, p. 91). 


\section{Referências}

ARCAS, P. Implicações da Progressão Continuada e do SARESP na Avaliação Escola: tensões, dilemas e tendências. 2009. 180f. Tese (Doutorado em Educação) Faculdade de Educação, Universidade de São Paulo, São Paulo, 2009.

BATLIWALA, S. El significado del empoderamento de las mujeres: nuevos conceptos desde la acción. In: LEÓN, M. Poder y empoderamiento de las mujeres. Santa Fe de Bogotá: T/M Editores, 1997. p. 187-211.

BETINI, G. A. Avaliação Institucional em Escolas Públicas de Ensino Fundamental de Campinas. 2009. 394f. Tese (Doutorado em Educação) Faculdade de Educação, Universidade Estadual de Campinas, Campinas, 2009.

BOURDIEU. P. Escritos de Educação. Petrópolis: Vozes, 1998. 251 p.

BRASIL. Decreto n. 6.094, de 24 de abril de 2007. Dispõe sobre a implementação do Plano de Metas Compromisso Todos pela Educação, pela União Federal, em regime de colaboração com Municípios, Distrito Federal e Estados, e a participação das famílias e da comunidade, mediante programas e ações de assistência técnica e financeira, visando a mobilização social pela melhoria da qualidade da educação básica. Disponível em:

http://www.planalto.gov.br/ccivil_03/_ato2007-2010/2007/decreto/d6094.htm. Acesso em: 14 jul. 2016.

BRASIL. Plano Nacional de Educação - PNE/Ministério da Educação. Brasília: INEP, 2014.

DESSEN, M. A.; POLONIA, A. C. A família e a escola como contextos de desenvolvimento humano. Paidéia (Ribeirão Preto), Ribeirão Preto, v. 17, n. 36, p. 21-32, abr. 2007.

E.U.A. No child left and behind. Disponível em:

<http://www.whitehouse.gov/news/reports/no-child-left-behind.pdf>. Acesso em: 01 ago. 2008.

FERRAROTTO, L. PROMASE: Análise de uma Experiência de Avaliação do Sistema Municipal de Ensino de Amparo. 2011. 193f. Dissertação (Mestrado em Educação), Faculdade de Educação, Universidade Estadual de Campinas, Campinas, 2011.

FREITAS, L. C. Eliminação adiada: o ocaso das classes populares no interior da escola e a ocultação da (má) qualidade do ensino. Educ. Soc., Campinas, v. 28, n. 100, p. 965-987, 2007. 
Os reformadores empresariais da educação: da desmoralização do magistério à destruição do sistema público de educação. Educ. Soc., Campinas, v. 33, n. 119, p. 379-404, jun. 2012.

Políticas de responsabilização: entre a falta de evidência e a ética. Cad. Pesq. São Paulo, v. 43, n. 148, p. 348-365, abr. 2013.

LAHIRE, B. Sucesso escolar nos meios populares: as razões do improvável. São Paulo: Ática, 1997. $367 \mathrm{p}$.

LOMONACO, B. P.; GARRAFA, T. C. A complexidade da relação escola-família em territórios vulneráveis. Cadernos CENPEC. v. 4, n. 6, p. 27-38, jun. 2009.

LÓPEZ, N. A escola e o bairro. Reflexões sobre o caráter territorial dos processos educacionais nas cidades. In. RIBEIRO, L. C. de Q.; KAZTMAN, R. (Org.). A cidade contra escola? Segregação e desigualdades educacionais em grandes cidades da América Latina. Rio de Janeiro: Letra Capital; FAPERJ, 2008. p. 327-362.

MENDES, G. S. C. V. Avaliação Institucional na Escola Pública: construções possíveis à contrarregulação. In: FREITAS, L. C. de; MALAVASI, M. M. S.; SORDI, M. R. de; MENDES, G. do S. C. V; ALMEIDA, L. C. (Org.). Avaliação e Políticas Públicas Educacionais: Ensaios Contrarregulatórios em Debate. 1 ed. Campinas: Edições Leitura Crítica, 2012. p. 171-194.

NOGUEIRA, C. M. M.; NOGUEIRA, M. A. A sociologia da educação de Pierre Bourdieu: limites e contribuições. Educação e Sociedade, Campinas, v. 23, n. 78, p.15-35, abr. 2002.

NOGUEIRA, M. A. Família e escola na contemporaneidade: os meandros de uma relação. Educação e Realidade. v. 31. n. 2, p. 155-169, jul./dez. 2006.

PORTES, E. A. O trabalho escolar das famílias de camadas populares. In: NOGUEIRA, M. A.; ROMANELLI, G.; ZAGO, N. (Org.) Família \& escola: trajetórias de escolarização em camadas médias e populares. Petrópolis: Vozes, 2000. p. 61-80.

RAVITCH. D. Reign of Error: the hoax of the privatization Movement and the Danger to American’s Public Schools. Alfred A. Knopf. New York, [s.n.], 2013. p. 403.

REALI, A. M. de M. R.; TANCREDI, R. M. S. P. A importância do que se aprende na escola: a parceria escola-famílias em perspectiva. Paidéia (Ribeirão Preto). Ribeirão Preto, v. 15, n. 31, p. 239-247, ago. 2005.

SAVIANI, D. O Plano de Desenvolvimento da Educação: análise do projeto do MEC. Educ. Soc., Campinas, v. 28, n. 100, p. 1231-1255, out. 2007. 
SCHNEIDER. M. P. Políticas de avaliação em larga escala e a construção de um currículo nacional para a educação básica. Rev. Cient., São Paulo, n. 30, p. 17-33, jan./abr. 2013.

SILVA, M. L. C. Q. A qualidade da escola pública na percepção de famílias populares. In: XIV Congresso Brasileiro de Sociologia, 14, 2009, Rio de Janeiro: PUC/RJ. p. 1-20, jul. 2009.

SORDI, M. R. L.; FREITAS, L. C. Responsabilização Participativa. Revista Retratos da Escola. Brasília. v. 7. n. 12, p. 87-99. 2013.

TODOS PELA EDUCAÇÃO. Estudos sociológicos investigam a relação entre família e escola. São Paulo. 4 de novembro de 2014. Disponível em:

$<$ http://www.todospelaeducacao.org.br/reportagens-tpe/31902/estudos-sociologicos-mostrama-relacao-entre-familia-e-escola/?pag=1>. Acesso em: 20 nov. 2014.

Pesquisa revela perfis de pais em relação à Educação dos filhos. São Paulo. 06 de novembro de 2014. Disponível em:

<http://www.todospelaeducacao.org.br/reportagenstpe/31839/pesquisa-revela-perfis-de-paisem-relacao-a-educacao-dos-filhos $>$. Acesso em: 20 nov. 2014.

.Temos que fortalecer o diálogo entre escola e família. São Paulo. 13 outubro de 2014. Disponível em: <http://www.todospelaeducacao.org.br/reportagens-tpe/31580/temosque-fortalecer-o-dialogo-entre-escola-e-familia>. Acesso em: 20 nov. 2014.

.Todos Pela Educação lança 5 Atitudes pela Educação. São Paulo. 14 de outubro de 2014. Disponível em: <http://www.todospelaeducacao.org.br/reportagens-tpe/31596/todospela-educacao-lanca-5-atitudes-pela-educacao>. Acesso em: 20 nov. 2014.

TRAVITZKI, R. ENEM: limites e possibilidades do Exame Nacional do Ensino Médio enquanto indicador de qualidade escolar. 2014. 322f. Tese (Doutorado em Educação). Faculdade de Educação, Universidade Estadual de São Paulo, São Paulo, 2014.

VIANA, M. J. B. Longevidade escolar em famílias de camadas populares - algumas condições de possibilidade. In: NOGUEIRA, M. A.; ROMANELLI, G.; ZAGO, N. (Org.) Família \& escola: trajetórias de escolarização em camadas médias e populares. Petrópolis: Vozes, p. 45-60, 2000.

ZAGO, N. Processos de escolarização nos meios populares - as contradições da obrigatoriedade escolar. In: NOGUEIRA, M. A.; ROMANELLI, G.; ZAGO, N. (Org.) Família \& escola: trajetórias de escolarização em camadas médias e populares. Petrópolis: Vozes, p. 17-44, 2000.

Recebido em: 14/02/2015 
Revisado em: 12/06/2015

Aprovado para publicação em: 07/07/2015

Publicado em: 31/08/2016 